\title{
A Study of Kinship Terms in Thai from the Gulture and Cognitive Perspectives
}

\author{
Han Jianghua * \\ (Sichuan University, China)
}

\begin{abstract}
The kinship terms of Thai can be divided into native kinship terms and foreign kinship terms based on the source, and can also be divided into civilian kinship terms and royal kinship terms based on the users. Thai kinship terms have different degrees of distinction in the following six dimensions: paternal and maternal, age, gender, the lineal and the collateral, consanguinity and affinity, users and use occasions. The unique use rules of Thai kinship terms reflect Thai people's concept of the distinctions between superiority and inferiority, seniors and juniors, intimacy and estrangement. In addition, Thai kinship terms reflect the marriage form that the Thais have experienced, and also reflect Thai people's ethnic cognitive orientation of experience familiarity, cognitive distance and metaphorical thinking.
\end{abstract}

Keywords: Thai language, kinship terms, culture, cognition

\section{Introduction}

Language, as one of the core parts of national culture, is the crystallization of an ethnic group's adaptability and adaptation to a specific environment, and is the key to spreading and inheriting the culture of an ethnic group (Zhang \& Ding, 2004:19). In an ethnic group's language, the kinship terms are a unique system. It records an ethnic group's family concept and social relations between people, as well as reflects the specific cultural and cognitive orientation of an ethnic group (Enke, 2018). The study of the kinship term system of a language lets us know about not only the corresponding culture of an ethnic group, but also the cognitive orientation of an ethnic group.

The Thai ethnic group in Thailand is an ethnic group with a long history and rich cultural heritage. The Thai language has been used by Thai people for hundreds of years, and it has

* Dr. Han Jianghua: Associate Research Professor of Linguistics, College of Literature and Journalism, Sichuan University, Chengdu City, Sichuan Province, China. This study is funded by Social Science Planning Fund Project of Sichuan Province, named "A Study of Semantic System of Thai languages from Cognitive Semantics" (SCI19B070); and is funded by Sichuan University (2018hhs-38); and is funded by "the Fundamental Research Funds for the central Universities" (YJ201801). E-mail: hanjianghuathai@sina. com. 
formed a complete and complex kinship term system. So far, scholars' research on Thai kinship terms has been mainly focusing on two aspects: semantic analysis and cross-lingual comparison. Many scholars have explored the semantic features and the underlying cultural factors behind the meaning of Thai kinship terms through componential analysis, such as Viphakun (1996) and Prasithrathsint $(1990,2001)$. Their studies point out that the analysis of the semantic features of Thai kinship terms can explore the Thai folk customs and changes of family concepts. In terms of cross-lingual comparison, some scholars have further demonstrated the genetic relationship between Thai and other languages by comparing kinship terms of these languages such as He (2003) and Huang (2006). Through the comparative study of kinship terms between Thai language and Zhuang language and combining the historical and cultural development history of the Zhuang and Thai ethnic groups, they have deeply demonstrated the view that the Zhuang and Thai languages have the same origin. And some scholars have explored the origin and evolution of loanwords in Thai kinship term system, such as Metcha (2005) and Lertjirawanich (2014). Through detailed comparative studies, they clarified the source of Chinese loanwords in Thai kinship terms including Chaozhou dialect, Hakka dialect, and Cantonese, and also explored the changes of these Chinese loanwords, intending to illustrate the relationship between language contact and language evolution.

However, we have not found study results that systematically discuss the social cultural and ethnic cognition behind the semantic system of Thai kinship terms as well as the rules of using Thai kinship terms. The theory of experience familiarity and cognitive distance believes that all of our perceptions are based on our physical experience, and the more we experience certain social facts, the more detailed we can know about them (Shu, Edwards \& Qi, 2013). Simultaneously, in the process of forming our perception of the outside world, the conceptual metaphor and metonymy serve as important cognitive means and thinking methods (Lakoff, 1993, Tang \& Rama, 2019). Therefore, studying Thai kinship terms from cultural and cognitive perspectives not only helps us to explore the social culture of the Thai people, but also helps us to further understand the ethnic cognitive orientation of the Thai people.

\section{Categorization of Thai kinship terms}

Thai kinship terms are a complicated system, which can be divided into different categories according to different standards.

According to the source, it can be divided into native language kinship terms and foreign language kinship terms. Native language kinship terms refer to a set of inherent kinship terms formed with the continuous development and improvement of Thai language. They are the main and core part of the Thai kinship term system. Foreign language kinship terms 


\section{A Study of Kinship Terms in Thai from the Culture and Cognitive Perspectives}

refer to kinship terms borrowed from other ethnic languages when Thai ethnic group is in the course of interaction with other ethnic groups. Foreign language kinship terms in Thai are mainly borrowed from Pali-Sanskrit and Chinese.

According to the users of Thai kinship terms, they can be divided into common kinship terms and royal kinship terms. Common kinship terms are kinship terms that can be used by all Thai people. Royal kinship terms refer to the kinship terms that are only allowed to be used by members of the Thai royal family.

The various categories of Thai kinship terms are as follows:

Table 1. Common kinship terms in Thai

\begin{tabular}{|c|c|c|c|}
\hline Kinship & Meaning & Kinship & Meaning \\
\hline$t^{h} u a t^{51} / p u^{2 l} t^{h} u a t^{51}$ & paternal great-grandfather & $t^{h} u a t^{51} / t^{3}:{ }^{33} t^{h} u a t^{51}$ & maternal great-grandfather \\
\hline$t^{h} u a t^{51} / j a:^{51} t^{h} u a t^{51}$ & paternal great-grandmother & $t^{h} u a t^{51} / j a: i^{33} t^{h} u a t^{51}$ & maternal great-grandmother \\
\hline$p u^{21}$ & paternal grandfather & $t a:^{33}$ & maternal grandfather \\
\hline$j a:^{51}$ & paternal grandmother & $j a: i^{33}$ & maternal grandmother \\
\hline$p^{h} \partial:^{.51}$ & father & $m \varepsilon:^{.51}$ & mother \\
\hline$p^{h} \supset:^{51} p^{h} u: a^{33}$ & father-in-law (husband's father) & $m \varepsilon:{ }^{5 l} p^{h} u: a^{33}$ & mother-in-law (husband's mother) \\
\hline$p^{h}{ }^{5}{ }^{51} t a:^{33}$ & father-in-law (wife's father) & $m \varepsilon:{ }^{51} j a: i^{33}$ & mother-in-law (wife's mother) \\
\hline$l u \eta^{33}$ & $\begin{array}{l}\text { uncle (father's or mother's elder } \\
\text { brother ) }\end{array}$ & $p a:^{51}$ & $\begin{array}{l}\text { aunt (father's or mother's elder } \\
\text { sister) }\end{array}$ \\
\hline $2 a:^{33}$ & $\begin{array}{l}\text { uncle (father's younger brother or } \\
\text { younger sister) }\end{array}$ & $n a:^{.55}$ & $\begin{array}{l}\text { uncle (mother's younger brother } \\
\text { or younger sister) }\end{array}$ \\
\hline$p a:^{51} s a^{21} p^{h} a i^{55}$ & \begin{tabular}{|l} 
aunt (father's or mother's elder \\
brother's wife)
\end{tabular} & $l u \eta^{33} k^{h} \partial: i^{215}$ & $\begin{array}{l}\text { uncle (father's or mother's elder } \\
\text { sister's husband) }\end{array}$ \\
\hline$P a{ }^{33} s a^{21} p^{h} a i^{55}$ & $\begin{array}{l}\text { aunt (father's younger brother's } \\
\text { wife) }\end{array}$ & $n a:^{55} s a^{21} p^{h} a i^{55}$ & $\begin{array}{l}\text { aunt (mother's younger brother's } \\
\text { wife) }\end{array}$ \\
\hline$P a:{ }^{33} k^{h} \partial: i^{215}$ & $\begin{array}{|ll|}\text { uncle (father's younger sister's } \\
\text { husband) }\end{array}$ & $n a:{ }^{55} k^{h} \partial: i^{215}$ & $\begin{array}{l}\text { aunt (mother's younger sister's } \\
\text { husband) }\end{array}$ \\
\hline$p^{h} i^{5 l}$ & $\begin{array}{l}\text { elder brother, elder sister, elder } \\
\text { cousin }\end{array}$ & $n \supset: \eta^{55}$ & $\begin{array}{l}\text { younger brother, younger sister, } \\
\text { younger cousin }\end{array}$ \\
\hline$p^{h} i^{51} s a^{2 l} p^{h} a i^{55}$ & $\begin{array}{l}\text { sister-in-law (elder brother's wife, } \\
\text { elder cousin's wife, husband's elder } \\
\text { sister, wife's elder sister) }\end{array}$ & $n \supset: \eta^{55} s a^{21} p^{h} a i^{55}$ & $\begin{array}{l}\text { sister-in-law (younger brother's } \\
\text { wife, younger cousin's wife, } \\
\text { husband's younger sister, wife's } \\
\text { younger sister) }\end{array}$ \\
\hline$p^{h} i^{51} k^{h} \partial: i^{215}$ & $\begin{array}{l}\text { brother-in-law (elder sister's } \\
\text { husband, elder cousin's husband, } \\
\text { husband's elder brother, wife's elder } \\
\text { brother) }\end{array}$ & nว: $\eta^{55} k^{h} \partial: i^{215}$ & $\begin{array}{l}\text { brother-in-law (younger sister's } \\
\text { husband, younger cousin's } \\
\text { husband, husband's younger } \\
\text { brother, wife's younger brother) }\end{array}$ \\
\hline$l u: k^{51}$ & son or daughter & la: $n^{215}$ & $\begin{array}{l}\text { nephew or niece, grandson or } \\
\text { granddaughter }\end{array}$ \\
\hline$l u: k^{51} k^{h} \partial: i^{215}$ & son-in-law (daughter's husband) & $l u: k^{51} s a^{2 l} p^{h} a i^{55}$ & daughter-in-law (son's wife) \\
\hline la: $n^{215} k^{h} \partial: i^{215}$ & son-in-law (niece's husband) & la: $n^{215} s a^{21} p^{h} a i^{55}$ & daughter-in-law (nephew's wife) \\
\hline $\operatorname{la}: n^{215} k^{h} \partial: i^{215}$ & grandson-in-law (granddaughter's & $l a: n^{215} s a^{21} p^{h} a i^{55}$ & granddaughter-in-law \\
\hline
\end{tabular}


Han Jianghua

\begin{tabular}{l|l|l|l}
\hline & husband) & & (grandson's wife) \\
\hline$l e: n^{55}$ & $\begin{array}{l}\text { great-grandson or } \\
\text { great-granddaughter }\end{array}$ & & \\
\hline
\end{tabular}

Table 2. Royal kinship terms in Thai

\begin{tabular}{|c|c|c|c|}
\hline Kinship term & Meaning & Kinship term & Meaning \\
\hline$p^{h} r a^{21} ? a i^{33} j a^{21} k a^{33}$ & grandfather & $p^{h} r a^{21}{ }^{2} a i^{33} j a^{21} k i^{33}$ & grandfather \\
\hline$p^{h} r a^{2 l} b i^{21} d a^{33}$ & father & $p^{h} r a^{21} m a: n^{33} d a^{33}$ & mother \\
\hline$p^{h} r a^{21} p i:{ }^{21} t u^{21} l a^{33}$ & uncle (father's brother) & $p^{h} r a^{21} p i^{21} t u t^{21} t s^{h} a^{33}$ & aunt (father's sister) \\
\hline$p^{h} r a^{2 l} t^{h} e: t^{21} t^{h} a^{33}$ & elder brother & $p^{h} r a^{21} p^{h} i^{51} n a: \eta^{33}$ & elder sister \\
\hline$p^{h} r a^{21} P a^{21} n u t^{21} t^{h} a^{33}$ & younger brother & $p^{h} r a^{21} n э: \eta^{55} n a: \eta^{33}$ & younger sister \\
\hline$p^{h} r a^{21} m a^{33} t u t^{21} t^{h} a^{33}$ & aunt (mother's sister) & $p^{h} r a^{2 l} p^{h} a: k^{2 l} k^{h} i^{2 l} n a i^{33}$ & nephew \\
\hline
\end{tabular}

Table 3. Pali-Sanskrit kinship terms in Thai

\begin{tabular}{|c|c|c|c|}
\hline Kinship term & Meaning & Kinship term & Meaning \\
\hline$? a i^{33} j a^{21} k a^{33}$ & grandfather & $2 a i^{33} j a P^{21} k_{i}{ }^{33}$ & grandmother \\
\hline$b i^{21} d a^{33}$ & father & $m a: n^{33} d a^{33}$ & mother \\
\hline$p i^{21} t u^{21} t a^{33}$ & uncle(father's brother) & $m a^{33} t u^{2 l} l a^{33}$ & uncle (mother's brother) \\
\hline$m a^{33} t u t^{21} t^{h} a^{33}$ & aunt (mother's sister) & $k a^{21} r a t^{21} t i^{21} p a^{33} t i^{33}$ & elder brother \\
\hline$P a^{21} n u t^{21} t^{h} a^{33}$ & younger brother & $\operatorname{bap}^{21} t^{h} a^{33}$ & elder sister \\
\hline$p^{h} a^{21} P u: n^{33}$ & younger sister & $b u t^{21} j_{i j} \eta^{33}$ & daughter \\
\hline$b u t^{2 l} t^{h} a: i^{33}$ & son & & \\
\hline
\end{tabular}

Table 4. Chinese kinship terms in Thai

\begin{tabular}{l|l|l|l}
\hline \multicolumn{1}{c|}{ Kinshipterm } & \multicolumn{1}{c|}{ Meaning } & \multicolumn{1}{c}{ Kinshipterm } & \multicolumn{1}{c}{ Meaning } \\
\hline $2 a^{33} \mathrm{ko \eta}^{33}$ & paternal grandfather & $l a u^{41} p \varepsilon^{22}$ & uncle (father's elder brother) \\
\hline$p a^{33} \mathrm{pa}^{24}$ & father & $s i{ }^{453}$ & aunt (father's younger brother's wife) \\
\hline$n i: a^{41}$ & mother & $2 i^{453}$ & aunt (mother's sister) \\
\hline$k v^{33}$ & elder brother & $s 0^{453}$ & sister-in-law (elder brother's wife) \\
\hline$t e^{453}$ & elder sister & $m a: i^{24} / m u: a i^{41}$ & younger sister \\
\hline
\end{tabular}

\section{Features of Thai kinship terms}

Through the analysis of Thai kinship terms in table 1 to table 4, we found that Thai kinship terms have many unique features. And we will summarize the features of Thai kinship terms from the following six aspects: paternal and maternal, age, gender, lineal and collateral, consanguinity and affinity, users and occasions of use.

\subsection{Paternal and maternal distinctions are not strict}

In Thai kinship terms, the paternal and maternal distinctions are different in different 
generations. Paternal and maternal lines are strictly distinguished in the generations of great-grandparents and grandparents. In the parental generation, apart from the father and mother's elder brother and elder sister who do not distinguish between paternal and maternal lines, the rest are strictly distinguished between paternal and maternal lines.

3.2 There are different distinctions between older and younger members in the same generation

No distinction is made between the older and the younger in the generation of great-grandfather and grandfather. Among the generation of parents, there is a strict age distinction based on parents: people older than parents and younger than parents have different appellations. Among the ego generation, people older than ego and younger than ego have different appellations. And no distinction is made between generations of sons, grandchildren, and great-grandchildren.

\subsection{Gender distinction is not strict}

The kinship terms in the generations of great-grandfather and grandfather have a strict gender distinction. However, there is no gender distinction in consanguinity kinship terms in the generations of ego, children, grandchildren, and great-grandchildren. In these generations, when it is necessary to specify a gender, the speaker only needs to add the word $t s^{h} a i^{33}$ 'male' or $s a u^{215}$ 'female' after the corresponding kinship terms.

However, in the parental generation, apart from the father and mother's younger brother and younger sister who do not distinguish between genders, the rest are strictly distinguished in terms of genders. In addition, all of affinity kinship terms in every generation have a strict gender distinction.

\subsection{The distinction between the lineal and the collateral is not strict}

In kinship terms of Thai, except for the children's generation where there is a strict distinction between the lineal and the collateral, the other generations have no distinction between the lineal and the collateral.

\subsection{The distinction between consanguinity and affinity is not strict}

There is no distinction between consanguinity and affinity in the generations of great-grandfather and grandfather. But consanguinity and affinity are distinguished in other generations. For most of the affinity kinship terms of Thai language, the word $k h$ ə: $i^{215}$ is added after the corresponding male consanguinity kinship terms to address male affinity, and the word $s a^{2 l} p^{h} a i^{55}$ is added after the corresponding female consanguinity kinship terms to address female affinity. Only the parents of one's spouse have special appellations. The husband's father is called $p^{h} \rho:{ }^{51} p^{h} u: a^{33}$, the husband's mother is called $m \varepsilon:{ }^{51} p^{h} u: a^{33}$, and the wife's father is called $p^{h}{ }^{5}:{ }^{51} t a::^{33}$, the wife's mother is called $m \varepsilon:{ }^{51} j a: i^{33}$.

3.6 There is a distinction between use objects and occasions of use

Common kinship terms of Thai can be used by all Thai people in any occasions, and the 
royal kinship terms can only be used among members of the royal family. The royal kinship terms are formed by adding the word $p^{h} r a^{2 l}$, which shows awe, before the borrowed Pali-Sanskrit kinship terms. Borrowed Pali-Sanskrit kinship terms in Thai are mainly used in written language (especially poetic style) and oral speech in formal occasions. It is generally not used in daily communicative discourse. Borrowed Chinese kinship terms in Thai language are generally used in Chinese descent communication circles, and Thai people who do not have Chinese descent generally do not use them.

\section{Rules of using Thai kinship terms}

Every kinship term in Thai has its fixed meaning. Therefore, we need to analyze the rules of using Thai kinship terms in addition to analyzing its system and characteristics. By investigating the specific use of Thai kinship terms, we found that the current use of Thai kinship terms mainly has the following rules:

\subsection{Use of kinship terms based on generation and age}

For elders or people who are of the same generation as we are but older than ourselves, the kinship terms will be used to directly refer to them. However, for younger generations or people who are of the same generation as we are but younger than ourselves, their names or nicknames are generally used to refer to them directly. For example, children call their father $p^{h} s^{5 l}$ and call their mother $m \varepsilon:^{5 l}$, while parents usually call their children by using the names or nicknames.

\subsection{Add different components after the same kinship term to distinguish age order}

When several relatives belong to the same generation, we can add a word indicating elder or younger after the kinship term to distinguish: the oldest person with ja: $i^{21}$ 'big', the second youngest person with $r:: \eta^{33}$ 'second', the third and other younger ones with "kinship term + name", and the youngest person with $l e k^{55}$ 'small'. For example, if one's father has several brothers, they can be called in order: $l u \eta^{33} j a: i^{21}$ 'first', lu $\eta^{33} r J: \eta^{33}$

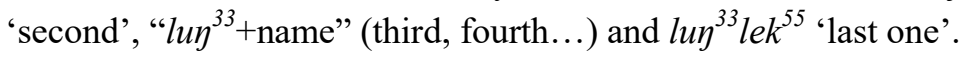

Another way to distinguish between several relatives belonging to the same generation is to use "kinship term + name" for everyone. And the "kinship term + name" is frequently used in contemporary Thai, while the use of ja: $i^{21}$ 'big', $r: \eta^{33}$ 'second', lek ${ }^{55}$ 'small' to distinguish among several relatives belonging to the same generation is not common.

4.3 The use of Thai kinship terms has differences between direct address and indirect address

The use of Thai kinship terms has differences between direct address and indirect address in communication. According to the different communication occasions and different communication objects, the use of Thai kinship terms is different.

For younger generations or people who are of the same generation as we are but younger 
than us, in the direct address, we often use their names to address them; while in the indirect address, we often use kinship terms to address them. However, for elders or people who are of the same generation as we are but older than us, either direct address or indirect address, we often use kinship terms to address (or refer to) them.

4.4 Add a polite word in front of kinship term to express euphemism and respect

Adding a polite word in front of kinship terms can be used in direct address and indirect address. The polite form of kinship terms can be divided into two forms: the polite form of common words and the polite form of royal words.

\subsubsection{Polite forms of common terms}

The polite form of common words is mainly formed by adding the politeness component $k^{h} u n^{33}$ or $t^{h} a n^{51}$ before the kinship terms. The word $k^{h} u n^{33}$ is added in front of common kinship terms to shows respect. It is generally used to address elders or people who are of the same generation as we are but older than ourselves, and is not used for younger generations or people who are of the same generation as we are but younger than ourselves. The $t^{h} a n^{5 l}$ is added in front of common kinship terms to show respect, but its extent of respect is higher than $k^{h} u n^{33} \cdot t^{h} a n^{51}$ is mainly used to address elders. When $t^{h} a n^{51}$ is used to address people who are of the same generation as we are, it often shows that the target has a higher social status or position.

\subsubsection{Polite forms of royal terms}

There are two forms of politeness in royal kinship terms. The first is to add $s e t^{21}$ in front of the royal kinship term. This form is often used in oral communication, and can only be used to address elders or people who are of the same generation as we are but older than ourselves. The other is to add $p^{h} r a^{21}$ in front of the royal kinship term. This form is generally not used for direct address.

\subsection{Thai kinship terms can be used in a generalized way}

Thai kinship terms are sometimes not used to address relatives, but to address people other than relatives. This phenomenon is actually a generalized use of kinship terms. That is, the kinship terms are transformed into social terms. Another phenomenon is that in discourse communication, one side of the communication uses asymmetric kinship terms to refer to the other (the two sides of the communication can be kinship or non-kinship). We refer to the use of the aforementioned Thai kinship terms as a generalized use of Thai kinship terms. From the perspective of users, the generalized use of Thai kinship terms can be divided into three categories:

\subsubsection{Using asymmetric kinship terms to address relatives}

In contemporary Thai society, people often like to use some asymmetrical kinship terms to address people who have a certain kind of kinship with them. For example, when a mother speaks to her child, she addresses her husband $p h s^{51}$ 'dad', her brother $l u \eta^{33}$ 
'uncle' and so on.

\subsubsection{Using kinship terms to address non-relatives}

In Thai society, people often get used to using kinship terms to refer to people who have no kinship with them, such as using $p u^{21}$ 'grandfather' to address male non-relatives who are of similar age to their grandfather, or using $p^{h} i^{5 l}$ to address male or female non-relatives who are older than them.

\subsubsection{Using asymmetric kinship terms to address non-relatives}

Another special generalized use of kinship terms in Thai is the use of asymmetric kinship terms to address non-relatives. For example, parents address children older than their children (non-relative relationships) as $p^{h} i^{5 I}$ 'older brother or older sister', and address the children younger than their children (non-relative relationships) as $n \supset: \eta^{55}$ 'younger brother or younger sister', and so on.

\subsection{Thai kinship terms have a simplifying trend}

In contemporary Thai society, there is a simplifying trend in the use of kinship terms. And there are three main types of simplification:

The first is the simplification of the kinship terms the generation of great-grandparents. People in this generation will be addressed by $t^{h} u a t^{5 l}$. There is no gender or maternalpaternal distinction.

The second is the simplification of the kinship terms of the generation of ego. Only age is distinguished in this generation. People who are older than us will be addressed by $p^{h} i^{51}$ 'older brother or older sister', while people who are younger than us will be addressed by $n s: \eta^{55}$ 'younger brother or younger sister'. There are no distinctions in gender, consanguinity and affinity, or the lineal and the collateral.

The third type no longer distinguishes consanguinity and affinity. All of the affinity will be addressed by kinship terms of consanguinity. For example, older sister-in-law will be addressed by $p^{h} i^{51}$ 'older sister', son-in-law and daughter-in-law will be addressed by $l u: k^{51}$ 'son or daughter', and so on.

\section{Social and cultural functions of Thai kinship terms}

In a nation, the kinship relationship between people seems to be a simple and common thing, but the kinship terms used in different nations are rich in meaning. This is because the kinship terms in each nation are not only closely related to the socio-political and economic systems that the nation has experienced, but also restricted by the socio-culture and custom of the nation (Ouyang, 2019). From this point of view, we can say that the kinship terms of a nation are the crystallization of the national wisdom in the historical development process, which inherits and reflects the development of the social culture of the nation. Through the system of kinship terms of a nation, we can explore the historical 


\section{A Study of Kinship Terms in Thai from the Culture and Cognitive Perspectives}

aspects of the society and the culture of that nation.

\subsection{The Thai marriage system reflected by the features of Thai kinship terms}

In the book Ancient Society (Morgan, 1877), Morgan divided the marriage system experienced by human beings into kinship marriage system, sub-kinship marriage system, dual marriage system and singular marriage system. The main reference of Morgan's division of the marriage system is the kinship terms of various ethnic groups. This shows that based on the kinship term system uploaded by history, we can conclude with certainty that an extinct family form suitable for this system did exist (Engels, 1957:35). Therefore, through certain features of the current Thai kinship terms system, we can infer the forms of marriage that Thai society has experienced.

In Thai, there are relative terms used to refer to multiple relatives, such as $l u \eta^{33}$, which can refer to either the father's brother or the mother's brother. $p a:{ }^{51}$ refers to both the father's sister and the mother's sister; $p^{h} i^{5 l}$ refers to older brother, older sister, and older cousin; $n:: \eta^{55}$ refers to younger brother, younger sister, younger cousin; $2 a:{ }^{33}$ refers to both the father's brother and the father's sister; $n a:{ }^{55}$ refers to both the mother's older sister and her younger sister; $l u: k^{5 l}$ refers to both the son and the daughter; etc. Some of these kinship terms in Thai do not distinguish among different ages in the same generation, some do not distinguish between genders in the same generation, and some do not distinguish between consanguinity and affinity in the same generation. This reflects that the Thai people's marriage and social organizations have experienced a marriage stage that is divided by generations, paying attention to generations and ignoring the older and the younger, as well as genders in the same generation.

In addition, in Thai kinship terms, $p^{h} i^{51} k^{h} \partial: i^{51}$ is used to address the husband's older brother or the husband of the older sister, $n \supset: \eta^{55} k^{h} \partial: i^{51}$ is used to address the husband's younger brother or the husband of the younger sister, $p^{h} i^{51} s a P^{21} p^{h} a i^{5 l}$ is used to address the wife's older sister or the wife of the older brother, and $n:: \eta^{55} \mathrm{sa}^{21} p^{h} a i^{51}$ is used to address the wife's younger sister or the wife of the younger brother. In these kinship terms, the $k^{h} \partial: i^{5 l}$ refers to the son from another family, and $s a^{21} p^{h} a i^{51}$ refers to the daughter from another family. These kinship terms reflect the extra-ethnic marriage system of the Thai people.

\subsection{Use of kinship terms reflects the seniority rules of Thai society}

Language is not only a product of social and cultural development but also a tool of social and cultural inheritance. Through language, we can know about many social and cultural contents related to the language. Through the use of Thai kinship terms, we can know about the seniority rules of Thai society. In Thai society, when we address a relative, if he (or she) is an elder or a person who is of the same generation as we are but older than ourselves, we must use kinship terms, and cannot address him (or her) by name (Fotaki \& 
Jingjit, 2018). Moreover, we usually add politeness words $k^{h} u n^{33}$ or $t^{h} a n^{51}$ in front of kinship terms to show respect. This reflects the respect that people have for the elderly in Thai society. However, when we address a relative, if he (or she) is a junior or a person who is of the same generation as we are but younger than ourselves, we usually do not use kinship terms, but instead just call them by name. This reflects the dignity of the elder.

\subsection{Use of kinship terms reflects the close relationship between people in Thai} society

As mentioned in section 4.5.1, in contemporary Thai society, people often like to use some asymmetrical kinship terms to address people who have a certain relationship with them. For instance, when a mother speaks to her child, she addresses her husband $p^{h} \supset:^{51}$ 'dad', and addresses her brother $l u \eta^{33}$ 'uncle'; parents address children who are older than their own children (non-relative relationships) as $p^{h} i^{51}$ 'brother or sister'; and so on. The function of using these kinds of kinship terms is to eliminate the mental distance between the two parties in the discourse communication to show the intimacy of the relationship. In addition, in the use of Thai kinship terms, elders often do not use kinship terms for juniors or the younger, but instead just call them by their names (usually nicknames) in verbal communication. It also follows the principle of intimacy in verbal communication. If in the conversation, the elders use the kinship terms to the junior or the younger, it will appear unfamiliar, and it will increase the mental distance between the two parties, which is not conducive to the smooth progress of communication.

\section{Cognitive interpretation of Thai kinship terms}

Language ability is part of people's general cognitive ability (Evans and Green, 2006:63-65). Language as the product of ethnic cognition is the of ethnic cognitive wisdom. Kinship terms, as an integral part of a language, have their inherent logical relationships. Behind these logical relationships is the cognitive orientation of the nations that use the language. Through the study of Thai kinship terms and their use, we can explore the cognitive orientations of the Thai people.

\subsection{Cognitive orientation I: Experience familiarity and cognitive distance}

The embodied philosophy believes that the mind is inherently embodied, that the thought is mostly unconscious, and that the abstract concepts are largely metaphorical (Lakoff \& Johnson, 1999:3). The interactive experience between people and the outside world is the basis for forming a conceptual system. Cognitive activities such as categorization, conceptualization, and reasoning all come from the experience of the human body. Concepts gain meaning and are understood by people through experiential, especially perceptual and motor, abilities (Lakoff \& Johnson, 1999:497). And all of our perceptions of the outside world are experiences based on our physical experience (Lakoff \& Johnson, 


\section{A Study of Kinship Terms in Thai from the Culture and Cognitive Perspectives}

1999:249; Wang, 2002). The more we experience certain social facts, the more detailed we can know about them, and vice versa (Wuyts, Colombo, Dutta \& Nooteboom, 2004; Marwede \& Herstatt, 2019). This is the experience familiarity and cognitive distance in cognition.

Vocabulary is a symbolic concept. Any vocabulary expresses a concept that has already been formed in our brain. The intergenerational differences in Thai kinship terms reflect the experience and familiarity in Thai people's cognition. Through the analysis of Thai kinship terms, we can see that Thai kinship terms have the most detailed distinction between parental kinship terms (see Table 1 for details). This is because in daily life, from childhood to adult, relatives that people most frequently contact are relatives of their parents' generation. When people have frequent contact with the relatives of the parents' generation, they have formed a multi-perspective cognition of them, and they are well aware of the subtle differences between them. These cognitions are reflected in the language by referring to them using different kinship terms.

Relatives of other generations lack cognition due to lack of experience, so that Thai people do not distinguish among them much. For example, relatives of people's great-grandfather and above generations, in reality, due to the limitation of life cycle, hardly come into contact with them. Some of their cognition is obtained through the narration of relatives or written records such as genealogy. Therefore, people often know very little about them. At present, in Thai, relatives of the great-grandfather and above generations are usually addressed only using the kinship term $t^{h} u a t^{51}$. In Thai language, $t^{h} u a t^{5 l}$ has the meaning of forebear or ancestor. From the use of this kinship term, we can see that Thai people's cognition of great-grandfather and above generations is very vague. Another example is the relatively special phenomenon in Thai, namely la: $n^{215}$, which is used to refer to the nephew, niece, grandson, and granddaughter. Many language researchers have noticed this phenomenon. This is also a more common phenomenon in the entire Thai languages. But for this phenomenon, language researchers have not yet given an explanation that is acceptable to many parties. We believe that the emergence of the use of this kinship term reflects Thai people's cognition of mental distance orientation for kinship. In Thai people's cognition, relatives to their own children, whether they are nephews, nieces, or grandchildren, all have a farther relationship with them. Although they belong to different generations, there is no difference in the mental cognitive distance, so they use the same kinship term to address.

In addition, it can be seen from table 1 that among Thai kinship terms, the kinship terms for relatives of the parents' generation is the largest in number and most complicated. When we take parental generation as the center, up as the generations increase and down as the generations decrease, the number of kinship terms in every generation is gradually 


\section{Han Jianghua}

decreasing. This fully reflects the experience familiarity and cognitive distance orientation in Thai people's cognition.

\subsection{Cognitive orientation II: Metaphoricality}

Metaphors and metonymies are important daily cognitive means and thinking methods (Lakoff \& Johnson, 1980:4-5; Lakoff, 1993). When people are performing cognition and reasoning, they often use metaphor or metonymy as a cognitive means. Through metaphor or metonymy, on the one hand, people can turn abstraction into concreteness, unfamiliarity into familiarity, complexity into conciseness, etc.; on the other hand, they can express some emotional cognition (Landau, Zhong \& Swanson, 2018; Wang, 2019; Han, 2019).

As a product of national cognition, any language and its verbal expressions contain a lot of metaphorical thinking and metaphorical and metonymic expressions (Reda, 2016; Qonsuli, Sharifi \& Dini, 2016). This kind of metaphorical thinking and metaphorical and metonymic expression also exists in the system of Thai kinship terms.

First of all, in Thai kinship terms, the essence of using $t^{h} u a t^{5 l}$ to refer to the relatives of the great-grandparents and above generations is a kind of metonymy, using the feature of old age to metonymize kinship. In addition to concisely referring to kinship, this metonymy also expresses people's respectful and awe-inspiring emotional cognition to the predecessors of the family.

Secondly, in contemporary Thai society, people often like to use some asymmetrical kinship terms to address people who have a certain relationship with them. For instance, when a mother speaks to her child, she addresses her husband $p^{h}{ }^{5}:{ }^{51}$ 'dad', and addresses her brother $l u \eta^{33}$ 'uncle'; parents address the children who are older than their own children (non-relative relationships) as $p^{h} i^{51}$ 'brother or sister'; and so on. This is also a metonymic use, where parents use their own children to metonymize themselves through blood bonds, and then address others as their own children. Through these metonymies, the speakers lower their own status and elevate the listener's status, which not only expresses respect for the listener, but also plays a role in reducing the mental distance between each other.

Third, using Thai kinship terms to address people other than relatives is essentially a metaphor. People establish a cross-space mapping based on the similarity between these non-relatives and their relatives in age, gender and other characteristics, so as to construct metaphors to achieve social addressing. This reflects Thai people's metaphorical cognitive orientation of turning strangeness into familiarity.

Fourth, the metaphorical thinking in Thai kinship terms is also reflected in the use of orientational metaphors. In the Thai kinship term system, the Thai people use the internal and external orientational metaphors to refer to consanguinity and affinity. For a family, consanguinities often occupy the majority, while affinities are relatively fewer than consanguinities. According to the figure and ground theory, when people recognize things, 
the first thing they pay attention to is the focused part, which is reflected by giving special speech marks in language expression. $k^{h} \partial: i^{215}$ and $s a^{2 l} p h a i^{33}$, which are used to indicate affinity relationship in Thai kinship terms, refer to "males from other families" and "females from other families" respectively. In the cognition of Thai people, people who join a certain family through a marital relationship are considered foreign and exist in opposition to the inner group of the consanguinity in the family.

\section{Conclusion}

The history of a language is often as long as the history of an ethnic group. Thai language, as a language used in real life, is actually the result of the long-term development of Thai society. It retains traces of social evolution in various periods in history. Through the analysis of Thai kinship terms, we can see that language is not a simple symbol, but the product of national cognition, the accumulation and refractions of national culture. As an important part of the Thai language, the Thai kinship terms are one of the important marks of Thai society's history and culture, which reflects the Thai people's national cognitive orientation and cultural development context from ancient time to the present. Through the study of Thai kinship terms, on the one hand, we come to understand the national cognitive orientation of the Thai people; on the other hand, it also provides us with a linguistic perspective to know about the development of Thai society.

\section{References}

Engels, F. 1957. The Origin of Family, Private Ownership and State [M]. Beijing: People's Publishing House.

Enke, B. 2018. Kinship Systems, Cooperation, and the Evolution of Culture [OL]. CESifo Working Paper. (https://papers.ssrn.com/sol3/papers.cfm?abstract_id=3144249)

Evans, V. \& M. Green. 2006. Cognitive Linguistics: An introduction [M]. Edinburgh: Edinburgh University Press.

Fotaki, M. \& R. Jingjit. 2018. Humanising Bureaucracy: Clan-oriented culture in the Thai civil service [A]. In S. Bice, A. Poole \& H. Sullivan (eds). Public Policy in the Asian Century [C]. London: Press for Palgrave Macmillan UK, 154-181.

Han, J-H. 2019. The Study of Thai Elephant Culture Based on the "Elephant Metaphors" in Thai Idioms [J]. Comparative Literature: East \& West, 3(2):148-162.

He, S. 2003. A Comparative Study of Kinship Terms between Zhuang and Thai [J]. Journal of Guangxi University for Nationalities (Philosophy and Social Science Edition), 25(1):149-154.

Huang, M. 2006. Cultural Connotation of Zhuang (Daxin dialect) and Thai Kinship Terms [J]. Academic Forum, (5):175-179.

Lakoff, G. \& M. Johnson. 1980. Metaphors We Live by [M]. Chicago: The University of Chicago Press.

Lakoff, G. 1993. The Contemporary Theory of Metaphor [A]. In A. Ortony (ed.). Metaphor and Thought [C]. Cambridge: Cambridge University Press, 202-251.

Lakoff, G. \& M. Johnson. 1999. Philosophy in the Flesh: The embodied mind and its challenges to western thought $[\mathrm{M}]$. New York: Basic Books.

Landau, M. J., C-B. Zhong \& T. J. Swanson. 2018. Conceptual Metaphors Shape Consumer Psychology [J]. ConsumPsychol Rev, (1):54-71. 


\section{Han Jianghua}

Lertjirawanich, M. 2014. A Comparative Study of Chinese and Thai Negative Appellations [D]. Doctoral Dissertation. Shanghai, China: East China Normal University.

Marwede. M. \& C. Herstatt. 2019. No Innovation for the Elderly? The Influence of Cognitive Distance in Corporate Innovation [J]. Creativity and Innovation Management, 28(3):355-367.

Metcha, S. 2005. A Comparative Study of Chinese and Thai Appellations [D]. Doctoral Dissertation. Nanjing, China: Nanjing Normal University.

Morgan, L. H. 1877. Ancient Society [M]. New York: Henry Holt And Company.

Ouyang, S. 2019. Cohesion and Division: Cross-cultural Translatability of Kinship Terms [J]. Journal of Yuan Dao, (1):266-278.

Prasithrathsint, P. 1990. Certain Significant Characteristics of Thai Culture as Evidenced in Thai Kinship Terms [J]. Thai Language and Literature, 7(1):34-47.

Prasithrathsint, A. 2001. A Componential Analysis of kinship Terms in Thai [A]. In K. Tingsabadh \& A. S. Abramson (eds). Essays in Thai linguistics [C]. Bangkok: Chulalongkorn University Press, 261-275.

Qonsuli, L. E., S. Sharifi \& M. M. Dini. 2016. Cognitive Linguistics: The study of discourse goals of using different types of figurative language [J]. Anglisticum, 2(5):124-131.

Reda, G. 2016. Ferdinand de Saussure in the Era of Cognitive Linguistics [J]. Language \& Semiotic Studies, (2):93-104.

Shu, H., G. Edwards \& C. Qi. 2013. Cognitive Distance [A]. Proceedings of SPIE - The International Society for Optical Engineering [C]. 290-296.

Tang, Q-H. \& W-C. Rama. 2019. Physical Practice and Cultural Metaphors: Based on the investigation of the Bimo and Suni of Yi people in Liangshan [J]. Social Science Research, (4):118-123.

Viphakun, W. 1996. The Connotation of Thai kinship Terms [J]. The Journal of Thammasat University, (3):16-29.

Wang, M-S. 2019. The Study on Cognitive Process and Translation of Conceptual Metaphor Understanding: Also discussing on the difference between "Translation Metaphor" and "Metaphor Translation" [J]. English Studies, (1):144-153.

Wang, Y. 2002. The Philosophical Foundation of Cognitive Linguistics: The philosophy of experience [J]. Foreign Language Teaching and Research, 34(2):82-89.

Wuyts, S., M. G. Colombo, S. Dutta \& B. Nooteboom. 2004. Empirical Tests of Optimal Cognitive Distance [J]. Social Science Electronic Publishing, 58(2):277-302.

Zhang, G-J. \& S-Q. Ding (ed.). 2004. A Course Book of Cultural Linguistics [M]. Beijing: Educational Science Press. 